\title{
PREPARATION OF NICKEL SUBSTRATES FOR COATED CONDUCTORS*
}

\author{
T. G. Truchan, F. H. Rountree, M. T. Lanagan, ${ }^{\dagger}$ S. M. McClellan, \\ D. J. Miller, and K. C. Goretta \\ Argonne National Laboratory, Argonne, IL
}

\author{
M. Tomsic \\ Eurus Technologies, Inc., Tallahassee, FL \\ R. Foley \\ Illinois Institute of Technology, Chicago, IL
}

September 2000

The submitted manuscript has been created by the
University of Chicago as Operator of Argonne National
Laboratory ("Argonne") under Contract No. W-31-109
ENG-38 with the U.S. Department of Energy. The U.S.
Government retains for itself, and others acting on its
behalf, a paid-up, nonexclusive, irrevocable worldwide
license in said article to reproduce, prepare derivative
works, distribute copies to the public, and perform publicly
and display publicly, by or on behalf of the Government.

Presented at 16th Intl. Conf. on Magnet Technology, Tallahassee, Sept. 26-Oct. 2, 1999; in IEEE Trans. Appl. Supercond. 10, 1130-1133 (2000).

*Work supported by the U.S. Department of Energy (DOE), Energy Efficiency and Renewable Energy, as part of a DOE program to develop electric power technology, under Contract W-31-109-Eng-38.

${ }^{\dagger}$ Current address Penn State University, University Park, PA. 


\section{DISCLAIMER}

This report was prepared as an account of work sponsored by an agency of the United States Government. Neither the United States Government nor any agency thereof, nor any of their employees, make any warranty, express or implied, or assumes any legal liability or responsibility for the accuracy, completeness, or usefulness of any information, apparatus, product, or process disclosed, or represents that its use would not infringe privately owned rights. Reference herein to any specific commercial product, process, or service by trade name, trademark, manufacturer, or otherwise does not necessarily constitute or imply its endorsement, recommendation, or favoring by the United States Government or any agency thereof. The views and opinions of authors expressed herein do not necessarily state or reflect those of the United States Government or any agency thereof. 


\section{DISCLAIMER}

Portions of this document may be illegible in electronic image products. Images are produced from the best available original document. 


\title{
Preparation of Nickel Substrates for Coated Conductors
}

\author{
T. G. Truchan, F. H. Rountree, M. T. Lanagan, S. M. McClellan, D. J. Miller, K. C. Goretta \\ Argonne National Laboratory, Argonne, IL, USA \\ M. Tomsic \\ Eurus Technologies Inc., Tallahassee, FL, USA \\ R. Foley \\ Illinois Institute of Technology, Chicago, IL, USA

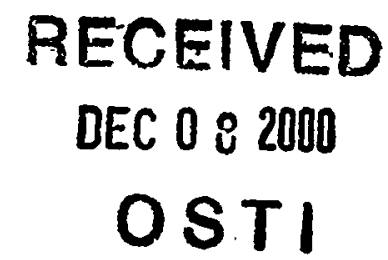

\begin{abstract}
Polycrystalline $\mathrm{Ni}$ has been used as a substrate for high-current, coated $\mathrm{YBa}_{2} \mathrm{Cu}_{3} \mathrm{O}_{\mathrm{X}}$ superconductors. For many conductors, $\mathrm{Ni}$ is rolled to large deformation and annealed to produce a cube texture. In this study, $\mathrm{Ni}$ was rolled to $>95 \%$ reduction and annealed in $5 \% \mathrm{H}_{2} / 95 \% \mathrm{He}$ at $300-1000^{\circ} \mathrm{C}$ for various times. The resulting substrates were examined by scanning electron microscopy, $\mathrm{X}$-ray and electron diffraction, and surface interferometry. Key determinations for the $\mathrm{Ni}$ were extent of in-plane and out-of-plane texture, surface smoothness, and grain size. The extent of texture was approximately independent of annealing temperature and increased slightly with annealing time. Annealing at temperatures $>600^{\circ} \mathrm{C}$ increased surface roughness, primarily due to grain-boundary grooving. Grain growth was fastest at $1000^{\circ} \mathrm{C}$ and was proportional to time to the 0.1 power.
\end{abstract}

Index term-Ni, Superconductors, Texture

\section{INTRODUCTION}

Strong biaxial texture is required for high transport critical current density in polycrystalline $\mathrm{YBa}_{2} \mathrm{Cu}_{3} \mathrm{O}_{\mathrm{x}}$ (YBCO) [1]. Coated conductors are therefore being developed for high-current applications [2,3]. One family of coated conductors achieves the required cube texture through thermomechanical processing of a metallic substrate such as $\mathrm{Ni}$ or $\mathrm{Ag}$ [2-4]. Most work to date has been conducted on $\mathrm{Ni}$, for which rolling is followed by annealing in a reducing environment. Thin film techniques are then used to deposit epitaxial $\mathrm{Y}_{2} \mathrm{O}_{3}$-stabilized $\mathrm{ZrO}_{2}$ and $\mathrm{CeO}_{2}$ buffer layers onto the textured metal to minimize superconductor contamination and match lattice parameters sufficiently well $[2,3]$. Ideally, the best metallic substrate for this type of conductor would be smooth, flat, and have perfect $\{001\}<100>$ cube texture.

During annealing of $\mathrm{Ni}$, in addition to developing the desired cube texture, grains grow, the surfaces of the individual grains roughen, and the grain boundaries become grooved. Although effects on coated conductors of surface smoothness of $\mathrm{ZrO}_{2}$ buffers layers [5] and of cracking in $\mathrm{CeO}_{2}$ buffer layers [6] have been reported, little attention has been focused on overall microstructural development in $\mathrm{Ni}$ substrates during annealing. Texture is, beyond question, the primary consideration. It is likely, however, that optimal texture can be achieved while simultaneously maximizing the smoothness of the Ni substrate. The goals of this work

Manuscript received September 27, 1999.

Work supported by the U.S. Department of Energy (DOE), Office of Energy Efficiency and Renewable Energy, as part of a DOE program to develop electric power technologv. under Contract W-31-109-Eng-38. were to quantify the effects of annealing on texture, grain size, and surface smoothness of rolled $\mathrm{Ni}$ substrates and to identify an annealing treatment that can produce excellent texture and good overall structure.

\section{EXPERIMENTAL PROCEDURES}

High-purity $\mathrm{Ni}(99.995 \%)$ sheet was rolled to $>95 \%$ reduction to a thickness of $80 \mu \mathrm{m}$. Uniform deformation and a smooth surface finish were obtained by controlling rolling conditions and using polished WC rolls. The resulting Ni strips were sheared into $1 \mathrm{~cm}^{2}$ coupons, which were cleaned with acetone and ethanol. The substrates were heat treated in a reducing environment $\left(5 \% \mathrm{H}_{2} / \mathrm{He}\right)$ at ambient pressure over a range of time $(0.5,2,4$, and $12 \mathrm{~h})$ and temperature $\left(250,400,600,800\right.$, and $\left.1000^{\circ} \mathrm{C}\right)$.

For grain-size determination, samples were etched by immersing in a mixture of $10 \mathrm{~mL} \mathrm{H} \mathrm{H}_{2} \mathrm{O}, 10 \mathrm{~mL}$ ethanol, $10 \mathrm{~mL} \mathrm{HCl}$, and $2 \mathrm{~g} \mathrm{CuSO}_{4}$ and were examined by scanning electron microscopy (SEM). Grain size determinations followed ASTM standards [7].

Texture development was examined by diffraction techniques. Conventional X-ray diffraction $2 \theta$ scans were used to determine initial texture development. Degrees of out-of-plane and in-plane texture were characterized by rocking curves and $\phi$ scans, respectively. SEM electron backscatter patterns (EBSPs) were used to quantitatively map the extent of misorientation between grains.

Surface roughness was characterized with a Zygo NewView 100 surface structure analyzer and MetroPro analysis software. By using coherent scanning white light interferometry, this system can measure topography and microstructure in three dimensions to a resolution of $0.1 \mathrm{~nm}$.

\section{RESULTS AND DISCUSSION}

Cube texture, i.e., $\{001\}<100>$ orientation, is known to develop directly from primary recrystallization in facecentered-cubic metals $[8,9,10]$. Because of ease of formability and resistance to oxidation, $\mathrm{Ni}$ has to date proved to be the best candidate as a substrate for coated conductors based on texture of the metal [2,3]. X-ray $2 \theta$ and $\phi$ scans indicated that for annealing at $400-1000^{\circ} \mathrm{C}$, the cube texture appeared to be strong and nearly independent of temperature. Shown in Fig. 1 are $\phi$ scans for 400 and $800^{\circ} \mathrm{C}$. Full width at half maximum values were $8-10^{\circ}$ for both in-plane and out-of-plane texture. 


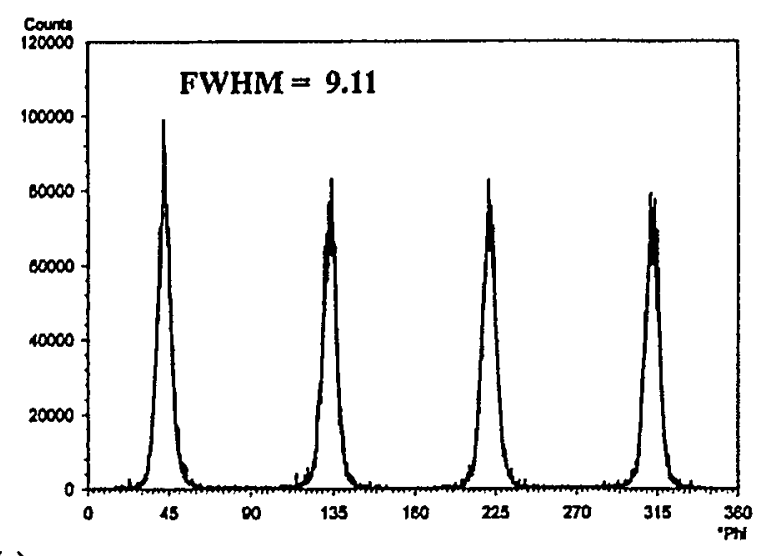

(a)

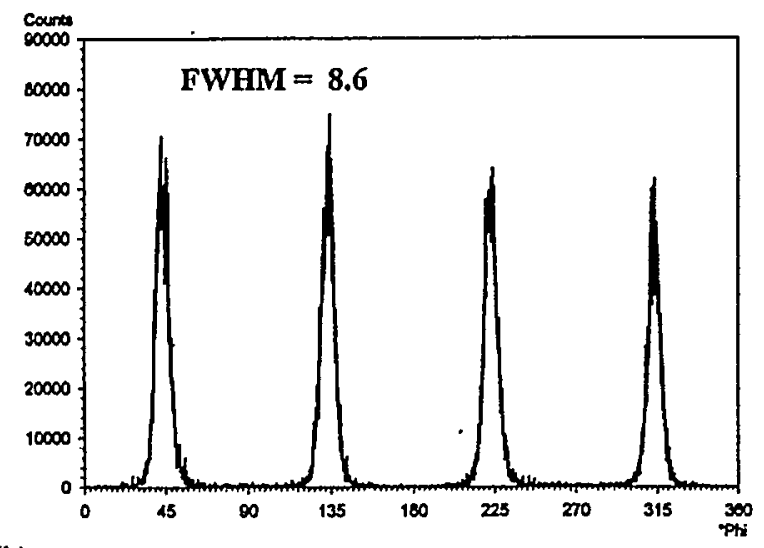

(b)

Fig. 1. $\phi$ scans for $\mathrm{Ni}$ heated at (a) 400 and (b) $800^{\circ} \mathrm{C}$ for $4 \mathrm{~h}$.

EBSP data more accurately indicated the influences of time and temperate on texture development. For example, annealing between 400 and $1000^{\circ} \mathrm{C}$ for $0.5 \mathrm{~h}$, showed no discernable difference in texture. However, longer times at temperature imparted slight improvements to the texture. These findings are consistent with expectations. In general, it has been reported that lower annealing temperatures and shorter annealing times lead to more diffuse cube orientations [8]. This effect may be due to abnormalities in orientation during the early stages of normal grain growth or the presence of twins [9].

Pole figures and $15^{\circ}$ threshold orientation maps (black pixels represent orientations $>15^{\circ}$ ) generated from the EBSPs for 400 and $1000^{\circ} \mathrm{C}$ samples are shown in Fig. 2. In general, results indicate that more than $80 \%$ of the grains are within $15^{\circ}$ and $70 \%$ are within $10^{\circ}$ of cube texture. It has been shown that misorientation angles between grains must be below $\approx 10^{\circ}$ for acceptable texture development of the buffer and $\mathrm{YBa}_{2} \mathrm{Cu}_{3} \mathrm{O}_{\mathrm{X}}$ layers [1-3]. Thus, all of the heat treatments produced relatively good textures.

Surface roughening and grain-boundary grooving were studied. The quality of the substrate surface is primarily dependent of the quality of the rolls used. For the scale-up to continuous production of coated conductors, it would be ideal if no polishing steps were to be needed. Chemical or mechanical polishing before the buffer deposition process is costly and may contaminate the surface and introduce strain into the grains. If polishing is to be avoided, grain-boundary grooving during annealing must be minimized. (a)
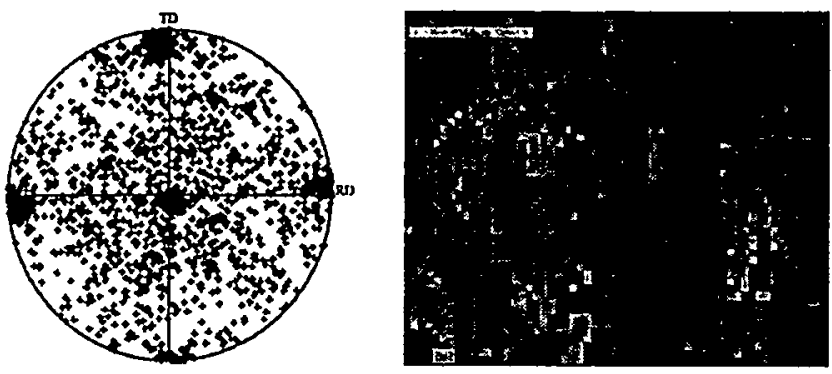

(b)
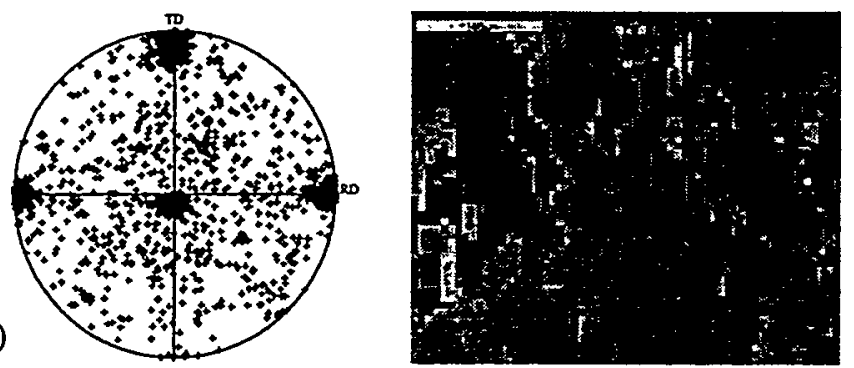

(c)
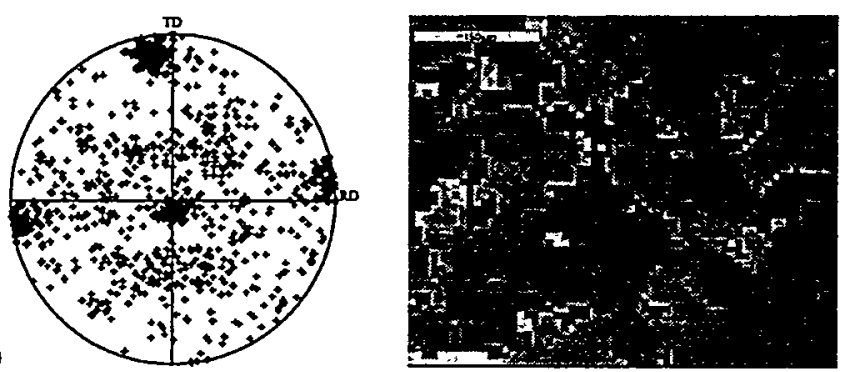

Fig. 2. Pole figures and $15^{\circ}$ orientation maps for (a) $0.5 \mathrm{~h}$ at $400^{\circ} \mathrm{C}$, (b) $12 \mathrm{~h}$ at $400^{\circ} \mathrm{C}$, and (c) $12 \mathrm{~h}$ at $1000^{\circ} \mathrm{C}$.

At equilibrium, where grain boundaries intersect the surface, minimization of free energy involves the creation of a groove with dihedral angle $\alpha$. Grooving can be described by: $\gamma_{b}=\gamma_{f . s .} \cos (\alpha / 2)$, where $\gamma_{b}$ and $\gamma_{\text {f.s. }}$ are the surface tensions of the grain boundary and the free surfaces, respectively. It has been shown that for long annealing times grooves can range between $0.1-1 \mu \mathrm{m}$ deep and up to $8 \mu \mathrm{m}$ wide [11]. Excessive grooving may contribute to the overall surface roughness and thereby degrade the overall quality of the buffer and superconductor layers. However, during annealing, surface diffusion can smooth the surface [12]. There is a balance between these two effects.

Figure 3 shows surface roughness as a function of time for annealing at 600 and $1000^{\circ} \mathrm{C}$; the roughness parameter $\mathrm{Ra}$ is defined by the absolute value of the arithmetic average deviation from the best-fit surface. From an initial value of $180 \AA$ for the as-rolled condition, $\mathrm{Ra}$ decreased slightly with increasing annealing times at $600^{\circ} \mathrm{C}$, but increased with time at $1000^{\circ} \mathrm{C}$. It is likely that diffusional surface smoothing dominated at $600^{\circ} \mathrm{C}$, whereas, at $1000^{\circ} \mathrm{C}$, grain-boundary grooving dominated; however, the effect saturated at $\approx 4 \mathrm{~h}$. To minimize the effects of rolling and better examine the influence grooving on surface roughness, some samples were mechanically polished before annealing to a $\mathrm{Ra}$ value of $50 \AA$. Figure 4 shows the surface roughnesses of polished and as-rolled samples that were annealed at various temperatures for 0.5 and $12 \mathrm{~h}$. 


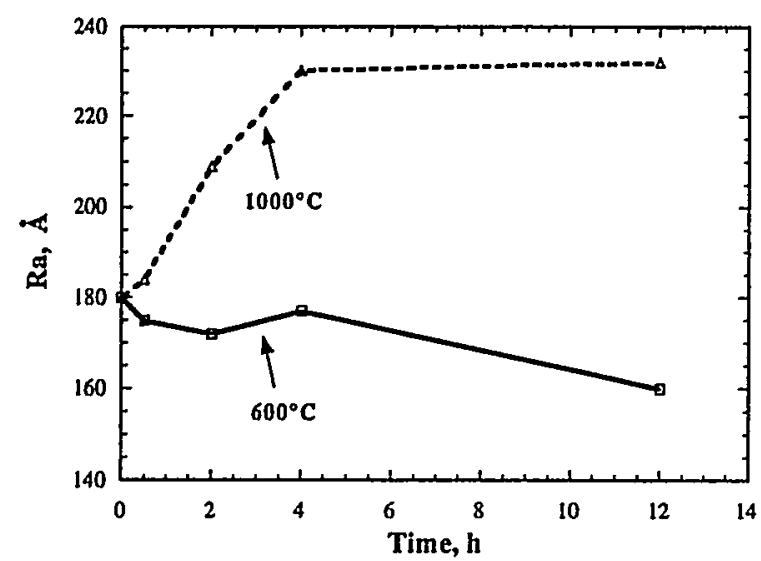

Fig. 3. $\mathrm{Ra}$ as a function of time for 600 and $1000^{\circ} \mathrm{C}$ annealing temperature.

Roughness remained approximately constant to $600^{\circ} \mathrm{C}$ and steadily increased with temperature due to thermal grooving. Initially as-rolled surfaces were resistant to roughening at $0.5 \mathrm{~h}$, regardless of temperature. This result is quite probably due to competition between diffusional smoothing and grain-boundary grooving. At long times, grooving dominated.

In general, depending on initial surface roughness, grooving can be expected to increase the surface roughness when it exceeds the roughness induced by rolling.

Individual line scans on polished surfaces confirmed that grooving became significant at $600^{\circ} \mathrm{C}$ and gradually increased at higher temperatures. Groove depth ranged from $<0.1 \mu \mathrm{m}$ at $600^{\circ} \mathrm{C}$ to $\approx 1 \mu \mathrm{m}$ at $1000^{\circ} \mathrm{C}$. Figure 5 shows the effect of grooving on adding to the overall surface roughness. As a consequence of the analysis software, any negative deviations from the centerline are plotted as positive deviations; thus, the grooves appear as protrusions. As annealing time and temperature increased, thermal grooving had a more profound influence on $\mathrm{Ra}$.

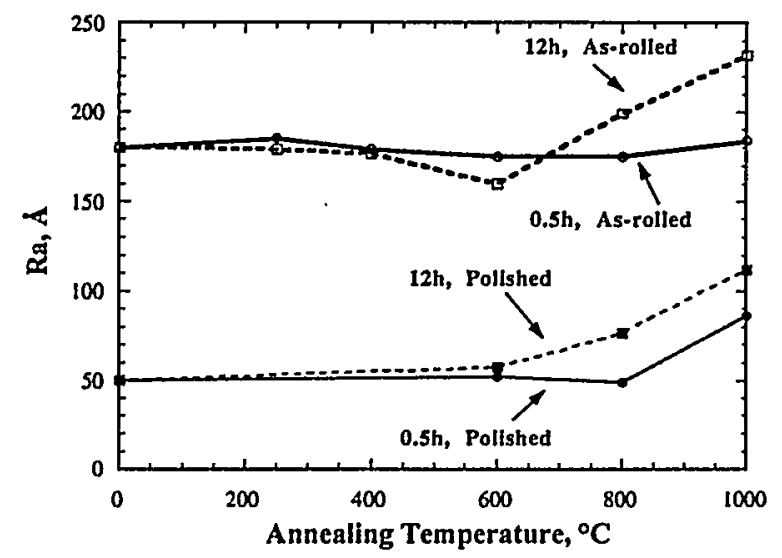

Fig. 4. $\mathrm{Ra}$ as a function of annealing temperature for as-rolled and polished samples.

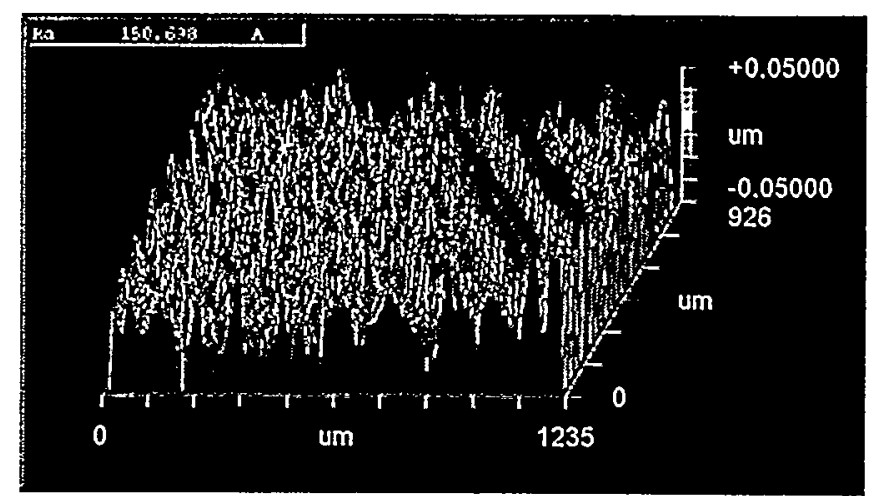

(a)

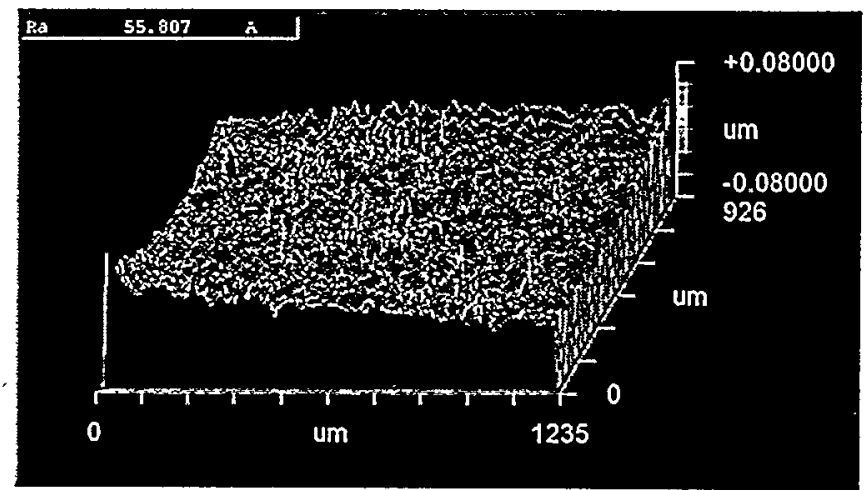

(b)

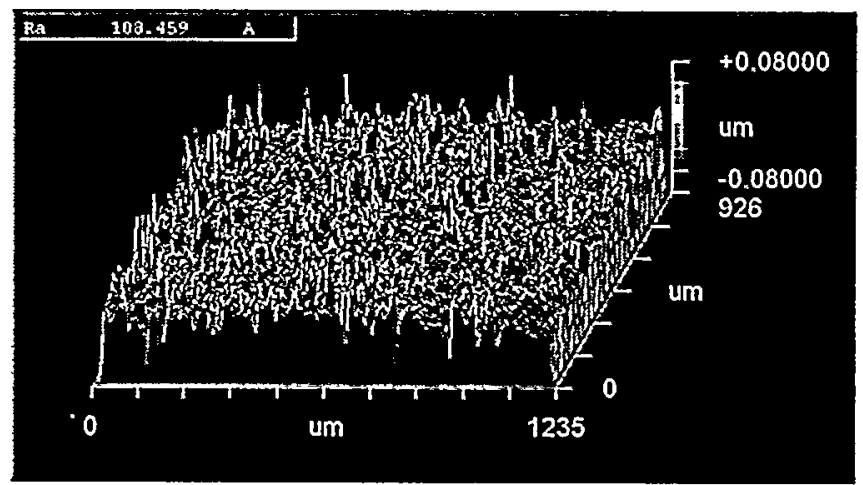

(c)

Fig. 5. Surface interferometry scans for $\mathrm{Ni}$ (a) as-rolled, (b) $0.5 \mathrm{~h}$ at $1000^{\circ} \mathrm{C}$, and (c) $12 \mathrm{~h}$ at $800^{\circ} \mathrm{C}$.

Grain size was also studied, primarily because for subsequent processing to form the superconductor, it is best if the grain size does not change. Furthermore, the larger the grain size the fewer the problems stemming from grain boundaries. Figure 6 shows an SEM image where the grains are distinctly separated by grain-boundary grooves. Average grain sizes after annealing were $\approx 30-40 \mu \mathrm{m}$, with rather large standard deviations. Nonuniform grain growth at short annealing times may be due to a sharp preferred texture. The large deformations introduced by the rolling process fostered rapid nucleation and growth during primary recrystallization and lead initially to a large population of small grains. Many grains were rapidly consumed during normal grain growth; however, the graingrowth rate quickly tapered off with time [11]. 


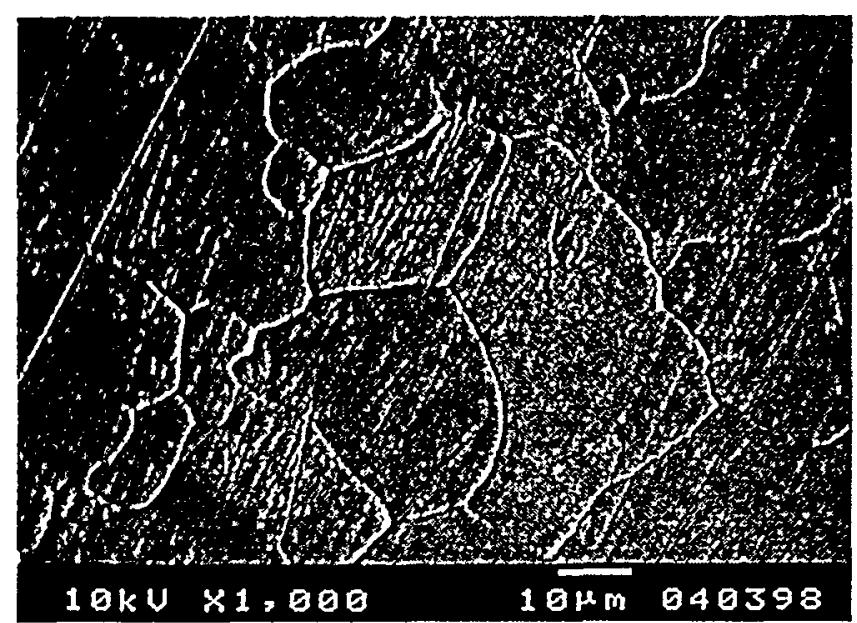

Fig. 6. SEM photomicrograph in topographic mode showing a polished $\mathrm{Ni}$ substrate heat treated at $1000^{\circ} \mathrm{C}$ for $4 \mathrm{~h}$.

An equation proposed by Beck $[13,14]$ for grain growth in metals is $G=k^{n}$, where $G$ is average grain size, $t$ is time, $\mathrm{n}$ is the grain-growth exponent, and $\mathrm{k}$ is related to an activation energy $\left(k=k_{0} \exp (-Q / R T)\right.$, where $k_{0}$ is a constant and $T$ is absolute temperature). The value of $n$ reaches a limit of 0.5 near the melting point, but for most metals $0.1 \leq$ $\mathrm{n} \leq 0.5$ [13]. Calculations showed $\mathrm{n} \approx 0.1$ at 600 and $1000^{\circ} \mathrm{C}$. This low value of $\mathrm{n}$ can be attributed to: (i) the fact that all anneals were conducted well below the melting temperature; (ii) the strong cube textures reduced the population of high-angle grain boundaries and, therefore, the driving force for boundary migration [13,15]; (iii) growth rates can be inhibited by free surfaces and our coupons were thin relative to the grain size $[13,14]$; and (iv) the grain-boundary grooves may have impeded growth.

\section{SUMMARY}

The multilayer architecture of coated conductors requires deposition of several of thin films under changing thermal conditions. The substrate surface must provide a stable foundation for all subsequent layers. For $\mathrm{Ni}$ sheets uniformly rolled to $>95 \%$ deformation, the development of a sharp cube texture was present for all heat treatment at $400-1000^{\circ} \mathrm{C}$, showing a slight improvement with longer annealing times.

Grain-boundary grooving had a significant contribution to the surface roughness, becoming significant at temperatures $\geq 600^{\circ} \mathrm{C}$. At temperature $<600^{\circ} \mathrm{C}$, surface smoothing was dominant. Grooving may also have the effect of slowing grain growth at higher temperatures. Grain growth of Ni during annealing was affected by heat treatment conditions, sheet thickness, and texture.

For a goal of development of a stable microstructure with grain size, low surface roughness, and a sharp cube texture, the following heat treatment may offer potential for producing the desired result. First, one should anneal rolled $\mathrm{Ni}$ for a long time at low temperature to form large uniform grains and smooth the surface. Then, one should anneal for a short time at high temperature to induce a small amount of grooving to stabilize the microstructure, but not long enough to increase surface roughness substantially.

\section{ACKNOWLEDGMENT}

We thank Mr. L. Hood, Dr. O. Girina, and Dr. T. Bloom of Inland Steel, East Chicago IN, for their expertise and assistance with the surface interferometry measurements.

\section{REFERENCES}

1. D. Dimos, P. Chaudhari, J. Mannhart, and F. K. LeGoues, Orientation dependence of grain-boundary critical currents in $\mathrm{YBa}_{2} \mathrm{Cu}_{3} \mathrm{O}_{7-2}$ bicrystals, Phys. Rev. Lett., Vol. 61, pp. 219-222, 1988.

2. A. Goyal, D. P. Norton, J. D. Budai, M. Paranthaman, E. D. Specht, D. M. Kroeger, D. K. Christen, Q. He, B. Saffian, F. A. List, D. F. Lee, P. M. Martin, C. E. Klabunde, E. Hartfield, and V. K. Sikka, High critical current density superconducting tapes by epitaxial deposition of $\mathrm{YBa}_{2} \mathrm{Cu}_{3} \mathrm{O}_{x}$ thick films on biaxially textured metals, Appl. Phys. Lett., Vol. 69, pp. 1795-1797, 1996.

3. D. K. Finnemore, K. E. Gray, M. P. Maley, D. O. Welch, D. K. Christen, and D. M. Kroeger, Coated conductor development: an assessment, Physica C, Vol. 320, pp. 1-8 (1999).

4. Y. Takahashi, K. Matsumoto, S. B. Kim, I. Hirabayashi, H. Akata, and $\mathrm{K}$. Higashiyama, In-plane alignment of $\mathrm{YBa}_{2} \mathrm{Cu}_{3} \mathrm{O}_{7-y}$ films realized by $\mathrm{CeO}_{2}$ buffer layer on textured Ag $\{100\}<001>$ tapes, IEEE Trans. Appl. Supercond., Vol. 9, pp. 2272-2275, 1999.

5. S. Oh, J. Yoo, K. Lee, J. Kim, and D. Youm, Comparative study on the crack formations in the $\mathrm{CeO}_{2}$ buffer layers for YBCO films on textured $\mathrm{Ni}$ tapes and Pt tapes, Physica C, Vol. 308, pp. 91-98, 1998.

6. C.-Y. Yang, S. E. Babcock, A. Goyal, M. Paranthaman, F. A. List, D. P. Norton, D. M. Kroeger, and A. Ichinose, Microstructure of electron-beam-evaporated epitaxial yttria-stabilized zirconia/ $\mathrm{CeO}_{2}$ bilayers on biaxially textured Ni tape, Physica C, Vol. 307, pp. 87-98, 1998.

7. ASTM Standard E 112-88, Standard test methods for determining average grain size, 1988.

8. H. Makita, S. Hanada, and O. Izumi, Recrystallization in cold-rolled pure nickel, Acta Metall., Vol. 36, pp. 403-412, 1988.

9. M. M. Borodkina and T. S. Orekhova, On the mechanism of formation of a cubic texutre in materials with f.c.c lattice, Phys. Met. Metall., Vol. 54, pp. 155-158, 1982.

10. P. Lejcek and V. Sima, Orientation relationships in the secondary recrystallization of pure nickel, Mater. Sci. Eng., Vol. 60, pp. 121-124, 1983.

11. W. Mullins, Theory of thermal grooving, J. Appl. Phys., Vol. 28, pp. 333-339, 1957.

12. W. Mullins, Flattening of a nearly plane solid surface due to capillarity, J. Appl. Phys. Vol. 30, pp. 77-83, 1959.

13. P. A. Beck, Studies on grain coarsening, J. Appl. Phys., Vol. 19, pp. 507-512, 1948

14. Recrystalization, Grain Growth and Textures, ed. H. Margolin, Amer. Soc. Met., Metals Park, OH, 1965.

15. W. R. Upthegrove and M. J. Sinnott, Grain boundary selfdiffusion of nickel, Trans. ASM, Vol. 50, pp. 1031-1046, 1957. 